\title{
Outcomes for symptomatic non-obstructed individuals and individuals with mild (GOLD stage I) COPD in a population based cohort
}

This article was published in the following Dove Press journal: International Journal of COPD

Rogelio Perez-Padilla'

Fernando C Wehrmeister ${ }^{2}$ Maria Montes de $\mathrm{Oca}^{3}$ Maria Victorina Lopez ${ }^{4}$ Jose R Jardim 5

Adriana Muiño ${ }^{4}$ Gonzalo Valdivia ${ }^{6}$ Ana Maria B Menezes²

On behalf of the PLATINO group

'National Institute of Respiratory Diseases, Mexico City, Mexico; ${ }^{2}$ Federal University of Pelotas, Pelotas, Brazil; ${ }^{3}$ Pulmonary Division, Hospital Universitario de Caracas, Universidad Central de Venezuela, Caracas, Venezuela; ${ }^{4}$ Faculty of Medicine, University of the Republic, Montevideo, Uruguay; ${ }^{5} \mathrm{Federal}$ University of Sao Paulo, Sao Paulo, Brazil; ${ }^{6}$ Pontificia Universidad Catolica de Chile, Santiago, Chile

Correspondence: Rogelio Perez-Padilla Instituto Nacional de Enfermedades Respiratorias, Tlalpan 4502, Col Sección XVI, I 4080 (CDMX), Mexico City, Mexico Email perezpad@gmail.com
Background: We aimed to study the adverse outcomes of symptomatic and asymptomatic non-obstructed individuals and those with mild COPD longitudinally in participants from three Latin-American cities.

Methods: Two population-based surveys of adults with spirometry were conducted for these same individuals with a 5- to 9-year interval. We evaluated the impact of respiratory symptoms (cough, phlegm, wheezing or dyspnea) in non-obstructed individuals, and among those classified as Global Initiative for Chronic Obstructive Lung Disease (GOLD) stage 1, COPD on exacerbation frequency, mortality and $\mathrm{FEV}_{1}$ decline, compared with asymptomatic individuals without airflow obstruction or restriction.

Results: Non-obstructed symptomatic individuals had a marginal increased risk of mortality (HR 1.3; 95\% CI 0.9-1.94), increased FEV 1 decline (-4.5 mL/year; 95\% CI -8.6, -0.4) and increased risk of $2+$ exacerbations in the previous year (OR 2.6; 95\% CI 1.2-6.5). Individuals with GOLD stage 1 had a marginal increase in mortality (HR 1.5; 95\% CI 0.93-2.3) but a non-significant impact on $\mathrm{FEV}_{1}$ decline or exacerbations compared with non-obstructed individuals.

Conclusions: The presence of respiratory symptoms in non-obstructed individuals was a predictor of mortality, lung-function decline and exacerbations, whereas the impact of GOLD stage 1 was mild and inconsistent. Respiratory symptoms were associated with asthma, current smoking, and the report of heart disease. Spirometric case-finding and treatment should target individuals with moderate-to-severe airflow obstruction and those with restriction, the groups with consistent increased mortality.

Keywords: spirometry, airflow obstruction, COPD, mild COPD, lung function decline, COPD exacerbations, screening for COPD

\section{Introduction}

COPD is the third leading cause of death in the world. ${ }^{1}$ It has been considered a consequence of rapid lung-function decline, but also the consequence of poor lung development either before or after birth. ${ }^{2}$

In the Proyecto Latinoamericano de Investigación en Obstrucción Pulmonar (PLATINO) study population, we described cross-sectionally the main characteristics of COPD in a population-based sample, ${ }^{3}$ and longitudinally, mortality rates and lungfunction decline according to COPD status in three Latin America metropolises (the PLATINO follow-up study). ${ }^{4}$ In this study individuals with post-bronchodilator (post-BD) Forced Expiratory Volume in 1 second/Forced Vital Capacity $\left(\mathrm{FEV}_{1} / \mathrm{FVC}\right)<0.70$ and $\mathrm{FEV}_{1} \geq 80 \%$ predicted $(\% \mathrm{P})$ known as Global Initiative for Chronic Obstructive Lung Disease (GOLD) stage 1 group $^{5}$ or mild COPD was by far the most numerous group of 
COPD found (8.5\% of the population studied in PLATINO, and $59 \%$ of identified COPD). The Burden of Obstructive Lung Diseases (BOLD) study reported a prevalence of GOLD 1 ranging from $1.4 \%$ to $15.5 \%$, with an average of $8.1 \%{ }^{6}$ In addition, false-positives in this group are frequent in advanced age, especially if the fixed ratio is used for the diagnosis of airflow obstruction. ${ }^{7}$ Furthermore, interventions specifically designed for mild COPD are nearly nil, in that the majority of clinical trials select individuals with reduced $\mathrm{FEV}_{1}$, frequently $\mathrm{FEV}_{1}<60 \% \mathrm{P}$. In the PLATINO's longitudinal study, the $\mathrm{FEV}_{1}$ was the main predictor of survival, ${ }^{4}$ as well as a predictor of lung-function decline. ${ }^{8}$ As GOLD stage 1 (mild COPD) individuals have a normal $\mathrm{FEV}_{1}$ by definition, we would expect a mild or non-significant impact on these outcomes.

Lung-function decline in GOLD stage I COPD patients was assessed previously in one large cohort, and asymptomatic participants had a slightly slower decline than those with chronic cough and phlegm. ${ }^{9}$ On the other hand, exacerbations have been associated with accelerated lung-function loss in subjects with established COPD, particularly those with mild disease. ${ }^{10}$ Recently, the relevance of respiratory symptoms in the prognosis, treatment selection and the natural history of COPD, especially in individuals with no airflow obstruction, has been emphasized, ${ }^{11}$ as well as the impact of mild airflow obstruction $^{12}$ and both were considered a relevant research issue by the American Thoracic Society (ATS) and the European Thoracic Society (ERS). ${ }^{13}$ Therefore, we conducted this study to determine the association of the presence of respiratory symptoms in non-obstructed individuals and of mild COPD with lung-function decline, exacerbations and mortality in COPD subjects from two population-based surveys.

\section{Method}

The study protocol for the baseline study was approved by the ethics committee of the Instituto Nacional de Enfermedades Respiratorias de Mexico, the Universidad Central de Venezuela, the Universidad Federal de Pelotas, and Universidad Federal de São Paulo in Brazil, the Universidad Pontificia Católica de Chile, and Hospital Maciel, Universidad de la República in Uruguay; the latter four approved the follow-up study. Participants signed an informed consent.

The detailed methods of the PLATINO baseline ${ }^{14}$ and follow-up studies ${ }^{15}$ are available elsewhere. Between the years 2003 and 2005, population-based surveys were conducted employing standardized methodology in five large LatinAmerican metropolitan areas: Sao Paulo (Brazil); Mexico City (Mexico); Montevideo (Uruguay); Santiago (Chile) and Caracas (Venezuela). We successfully interviewed 1,000 subjects aged 40 years or older in Sao Paulo, 1,063 in Mexico City,
943 in Montevideo, 1,208 in Santiago and 1,357 in Caracas. Spirometry testing was performed in 963 (97.9\%) subjects in Sao Paulo, 1,000 (98.3\%) in Mexico City, 885 (97.1\%) in Montevideo, 1,173 (99.8\%) in Santiago and 1,294 (98.4\%) in Caracas. ${ }^{3}$ The questionnaire, available at the PLATINO website,${ }^{36}$ is comparable to that used in the BOLD study, ${ }^{14}$ and included sections of the American Thoracic Society Division of Lung Diseases (ATS/DLD), European Community Respiratory Health Survey II, Lung Health Study instruments, the Medical Research Council (MRC) dyspnea scale and questions from the SF12 (a 12-item short form health survey) to assess overall health status. ${ }^{14}$

Spirometry was performed using an ultrasonic spirometer (EasyOne; ndd Medical Technologies, Zurich, Switzerland) before (pre-BD) and 15 minutes after the administration of $200 \mu \mathrm{g}$ of Salbutamol (post-BD) according to the ATS criteria of acceptability and reproducibility ${ }^{16}$ with $>90 \%$ of the tests fulfilling the ATS quality criteria.

Follow-up studies were conducted in Montevideo, Santiago and Sao Paulo 5, 6 and 9 years after the baseline surveys, respectively. Individuals were visited at their homes based on the contact information provided by them during the baseline exam. ${ }^{15}$

GOLD lung-function criteria for defining COPD was utilized: a post-BD $\mathrm{FEV}_{1} / \mathrm{FVC}<0.70$, with staging based on the percentage predicted for $\mathrm{FEV}_{1}: \mathrm{FEV}_{1}, \% \mathrm{P} \geq 80=$ Stage I (mild COPD); $\mathrm{FEV}_{1}, \% \mathrm{P} \geq 50$ and $<80=$ Stage II; $\mathrm{FEV}_{1}, \% \mathrm{P} \geq 30$ and $<50=$ Stage III; $\mathrm{FEV}_{1}, \% \mathrm{P}<30=$ Stage IV. ${ }^{5}$ GOLD stages $2-4$ defined as $\mathrm{FEV}_{1} / \mathrm{FVC}<0.7$ and $\mathrm{FEV}_{1}<80 \% \mathrm{P}$ were also analyzed for increasing the specificity of the COPD diagnosis. Restriction was defined as a post-BD FVC $<80 \% \mathrm{P}$ and a $\mathrm{FEV}_{1} / \mathrm{FVC} \geq 0.7,{ }^{17}$ to be consistent with GOLD stages.

We estimated the association of spirometric GOLD stages, with a set of adverse outcomes obtained during the survey (death, annual decline in $\mathrm{FEV}_{1}$, and the report of 2+ exacerbations in the previous year of second survey). Our reference group was the non-obstructed non-restricted asymptomatic participants: those who lacked a report of cough, phlegm (both even without a cold), wheezing (in the last year) and dyspnea (dyspnea $\leq 1$ according to the MRC scale). Adverse outcomes, especially death, ${ }^{4}$ as well as lung-function decline, ${ }^{8}$ were analyzed previously in detail, including the main risk factors. However, the aim of the present study was to investigate the impact of mild COPD and respiratory symptoms on decline, death and exacerbations. For the purpose of this study, COPD exacerbation was self-reported and defined by symptoms using the following questions ${ }^{18}: 1$ ) Have you ever had a period where your breathing symptoms got so bad that they interfered with your usual daily activities or 
caused you to miss work? 2) How many such episodes have you had in the past 12 months? 3) For how many of these episodes did you need to see a doctor in the past 12 months? 4) For how many of these episodes were you hospitalized in the past 12 months?

The risk of death during follow-up was estimated by fitting Cox proportional-hazard models, while the risk of two or more exacerbations in the previous year was calculated by fitting a logistic regression model, and the annual decline in post-BD $\mathrm{FEV}_{1}(\mathrm{~mL} /$ year) was calculated by subtracting the second measurement from the first and dividing the difference between the exact number of years between the two examinations ${ }^{8}$ in a multiple linear regression model.

As co-variables, we analyzed age; gender; current smoking (expressed as yes or no and also by the number of cigarettes smoked per day); cumulative smoking in packyears; obesity (BMI $>30 \mathrm{~kg} / \mathrm{m}^{2}$ ); years of education as an indicator of socioeconomic status; hour-years of exposure to biomass smoke while cooking (average number of years exposed multiplied by the average hours per day exposed); years of exposure to an occupation with dust, smokes or gases; previous physician diagnosis of asthma, COPD, diabetes or heart disease; or respiratory hospitalizations as children, obtained from a questionnaire. Utilization of health services was explored by the report of the use of any respiratory medication, exacerbations in the previous year requiring hospitalization, physician consultation or leading to missing days of work. We queried about self-perception of good or excellent health, feeling depressed or with little energy or calm.

Chronic bronchitis was defined as chronic phlegm (or chronic cough and phlegm) on the majority of the days of the week for 3 months of the year for two consecutive years. ${ }^{19}$

\section{Results}

Follow-up evaluations were conducted for 885 adults in Montevideo, 1,173 in Santiago and 963 in Sao Paulo; information was obtained for 758 (85.6\%), 993 (84.7\%) and 748 (77.7\%) subjects, respectively. Among these, 2,026 had a good quality post-BD spirometry test in both examinations. Follow-up rates for each independent-variable category were around $80 \% .{ }^{15}$ During follow-up, a total of 301 deaths among participants were documented.

The clinical characteristics in the two evaluations have been previously presented. ${ }^{4,8}$ Compared with the first examination, individuals with a follow-up exam were older, with less current smoking, and with slightly lower lung function.
Table 1 describes the characteristics of the analyzed groups: non-obstructed and non-restricted individuals, $\left(\mathrm{FEV}_{1} / \mathrm{FVC} \geq 0.7, \mathrm{FVC} \geq 80 \% \mathrm{P}\right)$, asymptomatic ( $\mathrm{n}=942$; $31.2 \%)$, the reference group, and symptomatic $(n=1,355$; $44.9 \%)$, the restricted group $(n=200 ; 6.6 \%)$, and the obstructed groups: GOLD stage $1(\mathrm{n}=323 ; 10.7 \%)$ and GOLD stages $2-4$ or moderate-to-severe $(n=201 ; 6.7 \%)$. As airflow obstruction increases there is tendency toward an increase the age, asthma, chronic bronchitis, previous tuberculosis (TB), and exposure to occupations involving dust, whereas the BMI decreases in the severely obstructed patients. Non-obstructed symptomatic individuals tend to concentrate a larger proportion of women with a previous diagnosis of asthma or COPD, currently smoking and with more frequent exacerbations in comparison with the asymptomatic non-obstructed individuals. Use of respiratory medications, missing days of work, hospitalizations and physician consultations associated with exacerbations, as well as poor perception of health were higher in symptomatic non-obstructed individuals and in those with more severe obstruction (Table 1). Table S1 separates GOLD stage 1 into asymptomatic $(n=100)$ and symptomatic individuals $(\mathrm{N}=223)$ the latter also with a higher proportion of women, previous asthma, current smoking, more use of respiratory medications and a more uncommon perception of good or excellent heath than the asymptomatic group.

Table 2 describes the association (odds ratio [OR] and $95 \% \mathrm{CI}$ ) of GOLD stages with the outcomes analyzed in the COPD population, unadjusted and adjusted by age, gender, BMI, education, comorbidities and smoking (adjusted 1) and all of the previous plus $\mathrm{FEV}_{1}$ post-BD (adjusted 2). The rate of deaths and frequent exacerbations tended to increase as the severity of airflow obstruction increased and in the restricted group, this mainly attributable to reduced $\mathrm{FEV}_{1}$ as an impact of the GOLD stage on mortality and exacerbations was considerably reduced adjusting by $\mathrm{FEV}_{1}$ (Table 2, adjusted 2 column). Similar models with GOLD stage 1 separated into asymptomatic and symptomatic groups are described in Table S2.

The presence of respiratory symptoms (dyspnea, cough or phlegm or wheezing) in non-obstructed individuals slightly increases the risk of death (adjusted HR 1.3, 95\% CI 0.90-1.94), whereas it significantly increases the risk of frequent exacerbations (OR 2.6; 95\% CI: 1.24-6.5) and lung-function decline $(-4.5 \mathrm{~mL} /$ year $)$ in excess to reference; 95\% CI: -8.6, -0.36) adjusting for age, gender, BMI, education, comorbidities, smoking and $\mathrm{FEV}_{1}$ post-BD (Table 2) (Figure 1). 
Table I Characteristics of the baseline groups of obstruction/respiratory symptoms (cough, phlegm, dyspnea or wheezing) evaluated*

\begin{tabular}{|c|c|c|c|c|c|}
\hline Characteristic & $\begin{array}{l}\text { Asymptomatic } \\
\text { non-obstructed } \\
(\mathrm{N}=942)\end{array}$ & $\begin{array}{l}\text { Symptomatic } \\
\text { non-obstructed } \\
(\mathbf{N}=I, 355)\end{array}$ & $\begin{array}{l}\text { GOLD } \\
\text { stage I } \\
(\mathbf{N}=323)\end{array}$ & $\begin{array}{l}\text { GOLD } \\
\text { stages 2-4 } \\
(\mathrm{N}=20 \mathrm{I})\end{array}$ & $\begin{array}{l}\text { Restrictive } \\
(\mathrm{N}=\mathbf{2 0 0})\end{array}$ \\
\hline & $\begin{array}{l}\text { Mean (SD) or } \\
\%(95 \% \mathrm{Cl})\end{array}$ & $\begin{array}{l}\text { Mean (SD) or } \\
\%(95 \% \mathrm{Cl})\end{array}$ & $\begin{array}{l}\text { Mean (SD) or } \\
\%(95 \% \mathrm{Cl})\end{array}$ & $\begin{array}{l}\text { Mean (SD) or } \\
\%(95 \% \mathrm{Cl})\end{array}$ & $\begin{array}{l}\text { Mean (SD) or } \\
\%(95 \% \mathrm{Cl})\end{array}$ \\
\hline Men $(95 \% \mathrm{Cl})$ & $45.5(42.4 ; 48.7)$ & $32.8(30.3 ; 35.4)$ & $55.4(49.9 ; 60.8)$ & $50.7(43.8 ; 57.7)$ & $43.5(36.7 ; 50.5)$ \\
\hline Age (years) & 55.5 (II.5) & $55.6(11.2)$ & $65.3(12.7)$ & $62.6(11.5)$ & $56.9(11.7)$ \\
\hline Height $(\mathrm{cm})$ & $161.2(9.9)$ & $158.8(9.4)$ & $161.0(9.9)$ & $162.0(9.7)$ & $160.7(10.5)$ \\
\hline BMI $\left(\mathrm{kg} / \mathrm{m}^{2}\right)$ & $27.2(4.5)$ & $28.9(5.8)$ & $27.2(5.2)$ & $26.9(5.8)$ & $29.1(5.9)$ \\
\hline FEV , pre-BD (L) & $2.86(0.8)$ & $2.64(0.7)$ & $2.3(0.7)$ & $1.6(0.6)$ & $2.01(0.67)$ \\
\hline FEV , post-BD (L) & $2.97(0.8)$ & $2.74(0.7)$ & $2.5(0.7)$ & $\mathrm{I} .7(0.6)$ & $2.07(0.65)$ \\
\hline FVC pre-BD (L) & $3.73(1.0)$ & $3.47(0.9)$ & $3.7(1.1)$ & $2.8(0.9)$ & $2.62(0.83)$ \\
\hline FVC post-BD (L) & $3.7 I(I .0)$ & $3.43(0.9)$ & $3.8(1.0)$ & $3.0(0.9)$ & $2.54(0.76)$ \\
\hline $\mathrm{FEV}_{1} / \mathrm{FVC}$ pre-BD & $77.1(6.0)$ & $76.1(6.1)$ & $64.4(6.8)$ & $55.4($ (II.I) & $77.0(7.5)$ \\
\hline $\mathrm{FEV}_{1} / \mathrm{FVC}$ post-BD & $80.4(5.1)$ & $79.8(4.8)$ & $64.9(4.6)$ & $57.1(10.7)$ & $81.3(6.0)$ \\
\hline Good quality pre-BD* $(95 \% \mathrm{Cl})$ & $94.8(93.2 ; 96.0)$ & $94.1(92.7 ; 95.2)$ & $92.0(88.4 ; 94.5)$ & $90.0(85.0 ; 93.5)$ & $95.0(90 ; 97)$ \\
\hline Good quality post-BD* $(95 \% \mathrm{Cl})$ & $93.3(91.6 ; 94.7)$ & $94.8(93.5 ; 95.9)$ & $91.5(87.8 ; 94.1)$ & $93.8(89.3 ; 96.5)$ & $94.0(89.7 ; 96.7)$ \\
\hline History of asthma $(95 \% \mathrm{Cl})$ & $5.5(4.2 ; 7.2)$ & $18.7(16.7 ; 20.9)$ & $16.7(13.0 ; 21.2)$ & $38.8(32.3 ; 45.8)$ & I5.5 (II.I; 2I.2) \\
\hline History of COPD $(95 \% \mathrm{Cl})$ & $0.9(0.5 ; 1.8)$ & $4.6(3.6 ; 5.8)$ & $5.6(3.5 ; 8.7)$ & $19.4(14.5 ; 25.5)$ & $6.0(3.4 ; 10.3)$ \\
\hline Current smoker $(95 \% \mathrm{Cl})$ & $20.7(18.2 ; 23.4)$ & $36.1(33.6 ; 38.7)$ & $36.2(3 I . I ; 4 I .6)$ & $38.3(31.8 ; 45.3)$ & $33.5(27.2 ; 40.4)$ \\
\hline Exacerbations in the last year & $0.01(0.3)$ & $0.4(9.5)$ & $0.1(0.6)$ & $5.2(37.1)$ & $2.0(25.8)$ \\
\hline $\begin{array}{l}\text { Two or more exacerbations in the } \\
\text { last year }\end{array}$ & - & $3.4(2.6 ; 4.6)$ & $2.5(1.2 ; 5.9)$ & $9.5(6.1 ; 14.4)$ & $5.3(2.5 ; 10.9)$ \\
\hline Previous tuberculosis & $1.9(1.4 ; 3.2)$ & $3.1(2.3 ; 4.2)$ & $5.0(3.0 ; 8.0)$ & $9.5(6.1 ; 14.4)$ & $5.0(2.7 ; 9.1)$ \\
\hline $\begin{array}{l}\text { Exposure to occupations with dust } \\
\text { (10+years) }\end{array}$ & $28.7(25.9 ; 31.8)$ & $30.5(28.1 ; 33.0)$ & $39.0(33.8 ; 44.5)$ & $4 I .3(34.6 ; 48.2)$ & $37.4(29.4 ; 46.1)$ \\
\hline $\begin{array}{l}\text { Physician diagnosis of COPD + } \mathrm{FEV}_{\mathrm{l}} \mathrm{I} \\
\mathrm{FVC}<0.7\end{array}$ & - & - & $5.6(3.5 ; 8.7)$ & $19.4(14.5 ; 25.5)$ & - \\
\hline $\begin{array}{l}\text { Physician diagnosed asthma + post-BD } \\
\mathrm{FEV}_{\mathrm{I}} / \mathrm{FVC}<0.7\end{array}$ & - & - & $16.7(13.0 ; 21.2)$ & $38.8(32.3 ; 45.8)$ & - \\
\hline $\begin{array}{l}\text { Wheezing last year + response to } \\
\mathrm{BD}+\text { post-BD FEV } / \text { FVC }<0.7\end{array}$ & - & - & $8.3(5.1 ; 13.2)$ & $23.1(15.9 ; 32.3)$ & - \\
\hline Chronic bronchitis (phlegm) & - & $10.9(9.3 ; 12.7)$ & $8.0(5.5 ;$ II .6$)$ & $18.9(14.0 ; 25.0)$ & $16.0(10.6 ; 23.5)$ \\
\hline Chronic bronchitis (cough or phlegm) & - & $17.5(15.6 ; 19.6)$ & $13.3(10.0 ; 17.5)$ & $26.4(20.7 ; 32.9)$ & $18.3(12.5 ; 26.0)$ \\
\hline $\begin{array}{l}\text { Chronic bronchitis (cough and } \\
\text { phlegm) }\end{array}$ & - & $4.7(3.7 ; 6.0)$ & $4.0(2.3 ; 6.8)$ & $10.9(7.3 ; 16.1)$ & $6.1(3.1 ; 8.1)$ \\
\hline Use of any respiratory medication & $7.0(5.5 ; 8.8)$ & $20.1(18.1-22.4)$ & $16.7(13.0-21.2)$ & $40.8(34.2 ; 47.8)$ & $16.0(10.6-23.4)$ \\
\hline Missing any day of work last year & $5.7(4.4 ; 7.4)$ & $15.2(13.4-17.2)$ & $13.3(10.0-17.5)$ & $30.8(24.8 ; 37.6)$ & I 3.7 (8.8-20.9) \\
\hline Respiratory hospitalization as children & $2.6(0.2-3.8)$ & $3.0(2.2-4.1)$ & $1.2(0.4-3.2)$ & $5.0(2.7 ; 9.1)$ & $3.0(1.3 ; 6.6)$ \\
\hline Respiratory hospitalization last year & - & $0.6(0.3-1.3)$ & $0.3(0.04-2.1)$ & $2.5(1.0 ; 5.9)$ & - \\
\hline Consultation with physician last year & $0.9(0.5-1.8)$ & $5.9(4.8-7.3)$ & $3.7(2.1-6.4)$ & $10.0(6.5 ; 15.0)$ & $6.1(3.1-11.8)$ \\
\hline $\begin{array}{l}\text { Self-perception of good or excellent } \\
\text { health }\end{array}$ & 87.I (84.8-89.1) & $62.1(59.4-64.6)$ & $74.9(69.9-79.4)$ & $57.2(50.2 ; 63.9)$ & $61.8(53.2-69.8)$ \\
\hline Feeling with little calm & $10.4(8.6-12.5)$ & $20.9(18.8-23.1)$ & $15.5(11.9-19.9)$ & $21.4(16.2 ; 27.7)$ & $19.0(13.2-26.8)$ \\
\hline Feeling depressed & $5.0(3.8-6.5)$ & $15.7(13.9-17.7)$ & $10.2(0.3-14.0)$ & $18.9(14.0 ; 25.0)$ & $12.2(7.6-19.1)$ \\
\hline Little energy & $4.6(3.4-6.1)$ & $14.9(13.1-16.9)$ & $9.9(7.1-13.7)$ & $20.4(15.3 ; 26.6)$ & $12.9(8.2-19.9)$ \\
\hline
\end{tabular}

Notes: *Symptoms were cough, or phlegm or wheezing or dyspnea $>$ I. BMI = weight/height ${ }^{2} ; \mathrm{SD}=$ standard deviation; pre-BD = before bronchodilator; post-BD = after bronchodilator. Good quality = three acceptable tests with two best $\mathrm{FEV}$, and $\mathrm{FVC}$ within $<150 \mathrm{~mL} ; 95 \% \mathrm{Cl}=95 \%$ confidence interval. Asthma-COPD overlap $=$ medical diagnosis of asthma (first definition) $+\mathrm{FEV} / \mathrm{FVC}<0.7$ post-BD or wheezing in the last year plus response to bronchodilator plus $\mathrm{FEV} / \mathrm{FVC}<0.7$ in the second definition, Chronic bronchitis is phlegm, cough or phlegm, or cough and phlegm most days for $>3$ months in a year for $>2$ consecutive years. "-" indicates 0 (nil).

Abbreviations: BD, bronchodilator; GOLD, Global Initiative for Chronic Obstructive Lung Disease. 
Table 2 Adjusted association (OR 95\% Cl) between GOLD stage at baseline, deaths, lung-function decline and exacerbations in the follow-up visit, with respiratory symptoms evaluated as cough, phlegm, dyspnea or wheezing

\begin{tabular}{|c|c|c|c|c|c|c|}
\hline \multirow[t]{3}{*}{ Obstruction/symptoms category } & \multicolumn{2}{|l|}{ Unadjusted } & \multicolumn{2}{|l|}{ Adjusted I } & \multicolumn{2}{|l|}{ Adjusted 2} \\
\hline & \multicolumn{6}{|l|}{ Deaths } \\
\hline & HR (95\% Cl) & $P$-value & HR (95\% Cl) & $P$-value & HR (95\% Cl) & $P$-value \\
\hline Non-obstructed asymptomatic & $\mathrm{I} .00$ (reference) & & I.00 (reference) & & I.00 (reference) & \\
\hline Non-obstructed symptomatic & $\mathrm{I} .40(0.98 ; 2.0 \mathrm{I})$ & 0.06 & $1.35(0.94 ; 1.95)$ & 0.101 & I.3। $(0.9 ; 1.9)$ & 0.157 \\
\hline $\begin{array}{l}\text { Mild obstruction (FEV }, \geq 80 \% \\
\text { of predicted) }\end{array}$ & $3.43(2.3 ; 5.2)$ & $<0.001$ & $1.53(1.01 ; 2.3)$ & 0.043 & $1.45(0.93 ; 2.3)$ & 0.099 \\
\hline $\begin{array}{l}\text { Moderate-severe obstruction } \\
\left(\mathrm{FEV}_{1}<80 \% \text { of predicted }\right)\end{array}$ & $5.6(3.7 ; 8.5)$ & $<0.001$ & $2.95(1.9 ; 4.5)$ & $<0.001$ & $2.1(1.2 ; 3.7)$ & 0.010 \\
\hline \multirow{3}{*}{$\begin{array}{l}\text { Restrictive (FVC }<80 \% \mathrm{P} \text { and } \\
\left.\mathrm{FEV}_{1} / \mathrm{FVC}>0.7\right)\end{array}$} & $2.8(1.69 ; 4.5)$ & $<0.001$ & $2.34(1.43 ; 3.84)$ & 0.001 & $1.91(1.09 ; 3.34)$ & 0.023 \\
\hline & \multicolumn{6}{|c|}{ Lung-function decline } \\
\hline & $\beta(95 \% \mathrm{Cl})$ & $P$-value & $\beta(95 \% \mathrm{Cl})$ & $P$-value & $\beta(95 \% \mathrm{Cl})$ & $P$-value \\
\hline Non-obstructed asymptomatic & 0.00 (reference) & & 0.00 (reference) & & 0.00 (reference) & \\
\hline Non-obstructed symptomatic & $-0.84(-4.90 ; 3.18)$ & 0.682 & $-3.55(-7.7 ; 0.59)$ & 0.093 & $-4.45(-8.6 ;-0.36)$ & 0.035 \\
\hline $\begin{array}{l}\text { Mild obstruction (FEV } 1 \geq 80 \% \\
\text { of predicted) }\end{array}$ & $-1.14(-7.6 ; 5.2)$ & 0.727 & $-0.35(-6.96 ; 6.24)$ & 0.915 & $-4.5 \mid(-11.3 ; 2.2)$ & 0.189 \\
\hline $\begin{array}{l}\text { Moderate-severe obstruction } \\
\text { (FEV },<80 \% \text { of predicted) }\end{array}$ & $4.14(-4.0 ; 12.3)$ & 0.318 & $4.5(-3.7 ; 12.8)$ & 0.278 & $-8.1(-17.4 ; 1.2)$ & 0.089 \\
\hline \multirow{3}{*}{$\begin{array}{l}\text { Restrictive (FVC }<80 \% \mathrm{P} \text { and } \\
\left.\mathrm{FEV}_{1} / \mathrm{FVC}>0.7\right)\end{array}$} & $19.0(11.0 ; 27)$ & $<0.001$ & $17.8(9.7 ; 25.8)$ & $<0.001$ & $7.7(-0.83 ; 16.4)$ & 0.077 \\
\hline & \multicolumn{6}{|c|}{ Exacerbations in past year (at least 2) } \\
\hline & OR $(95 \% \mathrm{CI})$ & $P$-value & OR $(95 \% \mathrm{CI})$ & $P$-value & OR $(95 \% \mathrm{CI})$ & $P$-value \\
\hline Non-obstructed asymptomatic & 1.00 (reference) & & 1.00 (reference) & & 1.00 (reference) & \\
\hline Non-obstructed symptomatic & $4.03(1.8 ; 9.1)$ & 0.001 & $2.81(1.22 ; 6.45)$ & 0.015 & $2.57(1.24 ; 6.49)$ & 0.027 \\
\hline $\begin{array}{l}\text { Mild obstruction (FEV, } \geq 80 \% \\
\text { of predicted) }\end{array}$ & $2.43(0.77 ; 7.76)$ & 0.131 & $2.74(0.82 ; 9.06)$ & 0.10 & $1.53(0.43 ; 5.56)$ & 0.514 \\
\hline $\begin{array}{l}\text { Moderate-severe obstruction } \\
\text { (FEV, }<80 \% \text { of predicted) }\end{array}$ & $7.5(2.7 ; 21.0)$ & $<0.001$ & $7.5(2.5 ; 22.1)$ & $<0.001$ & $1.50(0.40 ; 5.6)$ & 0.543 \\
\hline $\begin{array}{l}\text { Restrictive (FVC }<80 \% \mathrm{P} \text { and } \\
\mathrm{FEV} / \mathrm{FVC}>0.7)\end{array}$ & $5.9(2.0 ; 17.2)$ & 0.001 & $5.0(1.7 ; 14.9)$ & 0.004 & $1.45(0.43 ; 4.88)$ & $0.54 I$ \\
\hline
\end{tabular}

Notes: $95 \% \mathrm{Cl}, 95 \%$ confidence interval; inconsistent, different result between the two examinations. (I) adjusted by age, gender, BMI and education, comorbidities, restriction and after the first line by smoking (pack-years and cigarettes/day). (2) adjusted model I + FEV (post-BD) = the main determinant of decline.

Abbreviations: BD, bronchodilator; GOLD, Global Initiative for Chronic Obstructive Lung Disease.

Symptoms in non-obstructed individuals were associated with a prior diagnosis of asthma (OR 4.7; 95\% CI: 3.5-6.3) or heart disease (OR 2.2; 95\% CI: 1.7-2.8), with feminine gender (OR 1.5; 95\% CI: 1.3-1.8), current smoking (OR 3.1; 95\% CI: 2.6-3.8), passive smoking (OR 1.2; 95\% CI: 1.02-1.4) and previous dusty occupations (OR 1.5 ; $95 \%$ CI: $1.2-1.7$ ), in a multivariate logistic regression model. Asthma, wheezing and current smoking were also significantly associated with other combinations of symptoms: cough/phlegm, cough/phlegm/ dyspnea or chronic bronchitis, whereas a report of heart disease, passive smoking or occupational exposure was associated with some of these (See Table S3). Among the 1,355 non-obstructed symptomatic individuals, $36.1 \%$ were current smokers, $18.7 \%$ had a previous medical diagnosis of asthma, $40.1 \%$ were exposed to passive smoke, $2.7 \%$ were exposed to biomass smoke ( $26 \%$ were exposed previously), $56.0 \%$ worked previously in a dusty occupation and $18.9 \%$ reported the presence of heart disease. A total of $87 \%$ of the non-obstructed symptomatic subjects had at least one of the described risk factors compared with $74 \%$ of the asymptomatic individuals.

Mild COPD was weakly associated with increased mortality (HR 1.5; 95\% CI, 1.01-2.3), but not with increased risk of exacerbation (OR 2.8; 95\% CI, 0.8-9.06), nor a faster lung-function decline $(-0.35 \mathrm{~mL} /$ year; $95 \% \mathrm{CI}-7.0 ;+6.2)$ adjusting for age, gender, BMI, education, smoking and comorbidities (see Table 2, Figure 1 and Figure S1). 


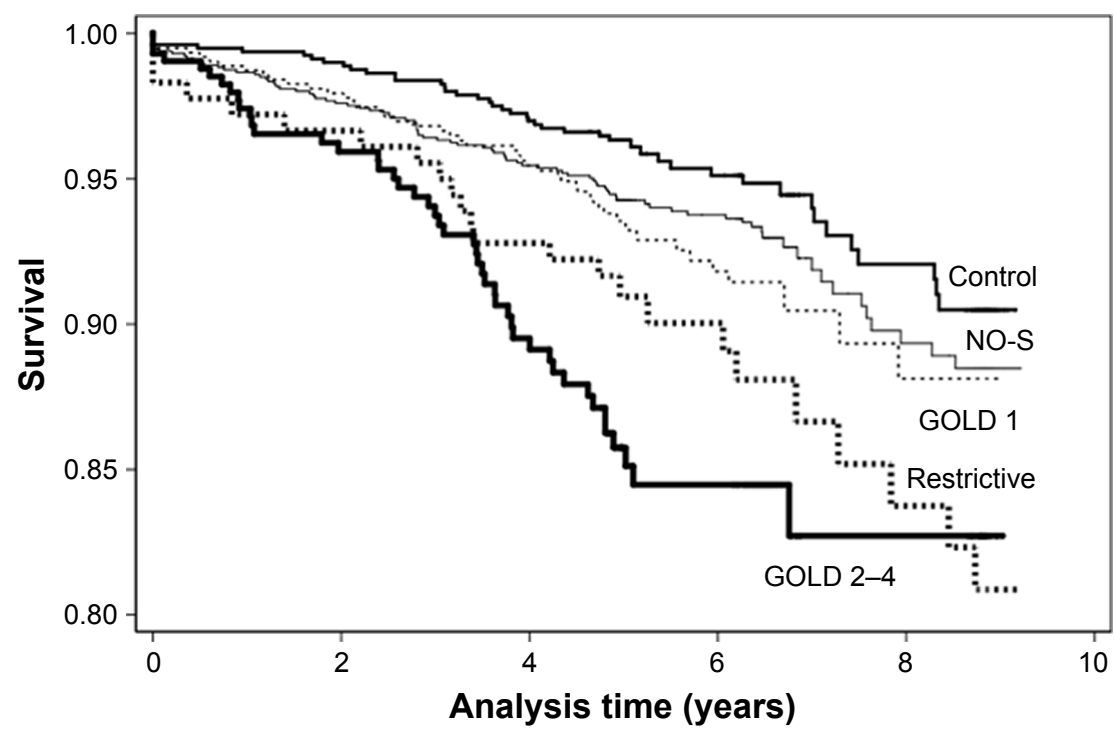

Figure I Survival curves of non-obstructed, non-restricted individuals with respiratory symptoms (cough, phlegm, dyspnea or wheezing), non-obstructed symptomatic (NO-S) and asymptomatic (Control), compared with those with airflow obstruction GOLD stage I (GOLD I), GOLD stages 2-4 (GOLD 2-4), and restrictive pattern, adjusted by mean age (57 years), feminine gender, education, pack-years of smoking and comorbidities (as in Adjusted I column, Table 2).

Notes: Symptomatic non-obstructed individuals had an increased risk of death than controls and stage-I individuals but better outcome than individuals with moderate-tosevere airflow obstruction and restrictive spirometric defect. Survival of GOLD stage I overlaps with non-obstructed symptomatic individuals.

Abbreviation: GOLD, Global Initiative for Chronic Obstructive Lung Disease.

Moderate and severe airflow obstruction (GOLD stages 2-4) consistently increased the risk of death (HR 2.95, 95\% CI 1.9-4.5, Figure 1 and Figure S1), and frequent exacerbations (OR 7.5, 95\% CI; 2.5-22.1) whereas this did not predict a more pronounced decline in lung function unless adjusted by baseline post-BD FEV ${ }_{1}$ (the most relevant predictor) (Table 2). Individuals with a spirometric restrictive pattern had increased the risk of death (HR 2.34, 95\% CI 1.4-3.8) and frequent exacerbations (OR 5.0, 95\% CI 1.4-14.9) but not increased $\mathrm{FEV}_{1}$ decline (Table 2, Figure 1)

GOLD stages 2-4, not present in the first evaluation, appeared in 55 individuals in the second (incident GOLD 2-4), distributed at baseline more frequently in the symptomatic groups (non-obstructed and with GOLD stage 1) (Table S4). Significant predictors of incident GOLD 2-4 included the presence of symptoms at baseline (OR 2.1; 95\% CI, 1.0-4.3), as well as asthma (OR 2.9; 95\% CI, 1.5-5.5), masculine gender (OR 2.5; 95\% CI, 1.4-4.5) and current smoking (OR 1.8; 95\% CI, 1.0-3.2) (see Table S5, Adjusted 1), but baseline post-BD FEV ${ }_{1}$ was the most relevant predictor (OR $0.34 ; 95 \%$ CI, 0.21-0.55) and once included in the model (see Table S5, Adjusted 2), the association with symptoms disappeared but persisted with asthma or smoking.

\section{Discussion}

We have described the association of the presence of symptoms in non-obstructed individuals and of mild COPD
(GOLD stage 1) with several remarkable outcomes (death, frequent exacerbations, airflow obstruction and lung-function decline) in a population-based follow-up study carried out in three Latin-American cities. We found that respiratory symptoms in non-obstructed individuals and mild airflow obstruction, in adjusted models, had mild adverse outcomes compared with those of asymptomatic non-obstructed individuals, whereas individuals with a reduced $\mathrm{FEV}_{1} \%$ (GOLD stages 2-4) or reduced FVC entertain a substantially increased risk of death and exacerbations. In addition, non-obstructed symptomatic individuals exhibit in general a slightly faster decline in $\mathrm{FEV}_{1}$.

Several studies have found adverse outcomes in symptomatic individuals and in those with mild COPD. In one population-based study, ${ }^{9}$ individuals with symptomatic stage 1 COPD had a faster decline in $\mathrm{FEV}_{1}(-9 \mathrm{~mL} /$ year in excess to reference), increased respiratory-care utilization (OR 1.6) and a lower quality of life than asymptomatic subjects with normal lung function. ${ }^{9}$ These changes were not observed in individuals with asymptomatic stage 1 COPD. In the COPDGene study, ${ }^{10} 27.4 \%$ of GOLD stage 1 patients experienced a mean exacerbation rate/year of 0.18 compared with 0.13 of GOLD stage- 0 and 0.89 of GOLD stage- 4 patients, respectively. From 745 participants with GOLD stage 1 (from a total of approximately 4,000 patients with COPD), only 55\% reported being exacerbation-free, $20 \%$ reported two or more exacerbations in the previous year and $9.6 \%$ reporting one or more hospitalizations. ${ }^{20}$ 
The results of the present manuscript reinforce first, the efforts to identify systematically individuals with moderate and severe airflow obstruction (GOLD stages 2-4), characterized by a reduced $\mathrm{FEV}_{1}$, the main predictor of increased death rate ${ }^{4}$ and of decline in lung function ${ }^{8}$ as well as those with reduced $\mathrm{FVC}<80 \% \mathrm{P}$, with a restrictive spirometric pattern. Second, in contrast to previous studies, ${ }^{9,10}$ we observed mild adverse outcomes of GOLD stage 1, supporting the recommendations of prioritize the identification of moderate-to-severe COPD. ${ }^{21,22}$ Individuals with GOLD stage 1 , comprise a numerous group among population-based cohorts ( $8.4 \%$ of the total PLATINO population in baseline) compared with GOLD stages 2-4 (5.6\%). Expenses and efforts to identify spirometrically undiagnosed COPD would be considerably reduced focusing for moderate-to-severe airflow obstruction, what can be achieved for example by selecting for diagnostic spirometry individuals with a reduced PEFR or simplified spirometry. ${ }^{23,24}$ Individuals with moderate-to-severe COPD are precisely those with more proved beneficial interventions in addition to stopping smoking ${ }^{21,22}$ as most controlled clinical trials testing medications for COPD exclude individuals with mild airflow obstruction.

Third, in line with previous studies ${ }^{11}$ the presence of respiratory symptoms in non-obstructed individuals requires further evaluation as adversely impact prognosis. In our study, any combination of respiratory symptoms (cough, phlegm, dyspnea or wheezing, but also classic chronic bronchitis) in non-obstructed individuals was associated with previous diagnosis of asthma ${ }^{10}$ or wheezing in the last year, and this may suggest asthma undertreatment and underdiagnosis. Symptoms were also associated with current smoking, passive smoking, exposure to dusty occupations and a report of a heart disease. Those lacking one of the explored risk factors in the present study could include several respiratory diseases, gastroesophageal reflux or upper airway diseases, which require detailed evaluation and specific treatment.

Smokers with mild airflow obstruction, and also nonobstructed smokers, may present gas exchange abnormalities and exercise limitation ${ }^{12,25-32}$ or significant changes of emphysema on CT scanning. ${ }^{33,34}$ In fact, phenotyping individuals with mild COPD based on CT alterations has been proposed. ${ }^{35}$ The persistently symptomatic population feels unhealthy, utilizes more health services and has adverse outcomes, although fewer of these than individuals with moderate-to-severe airflow obstruction. Therefore efforts to stop smoking and exposures and treating properly asthma should be emphasized as priorities for symptom management.

As limitations, we have observed these subjects on solely two occasions and were able to perform a second evaluation only in three cities from the five done the baseline. In addition, the percentage of individuals with severe airflow obstruction is small, although the main objective of the study was to compare GOLD stage 1, with non-obstructed individuals. Second, we utilized a definition of exacerbation based on subjects' report of breathing symptoms, interfering with daily activities or work, but also identified those events requiring a physician visit or hospitalization, likely less subject to inaccurate recall.

The main strengths of this study include the populationbased sampling, the high quality of the post-BD spirometry tests, ${ }^{4}$ and the relatively high rates of follow-up after 6-9 years. In contrast to the large COPD cohorts, our population-based study has a proper non-obstructed population control key for numerous relevant comparisons, with and without respiratory symptoms, previous smoking or abnormalities in FVC.

\section{Conclusion}

The presence of respiratory symptoms (cough, phlegm, wheezing, dyspnea) in non-obstructed individuals as well as mild airflow obstruction demonstrated a mild adverse impact on mortality and exacerbations and were associated with current smoking, exposure to other pollutants and bronchial asthma, requiring among other things improved anti-smoking strategies in health care. Individuals with reduced $\mathrm{FEV}_{1}$ or FVC (moderate-to-severe airflow obstruction and those with spirometric restriction) had the highest mortality risk and constitute a priority target for diagnosis and treatment.

\section{Acknowledgments}

We thank Asociación Latinoamericana de Tórax (ALAT) for helping in the design of the project and for funding part of the project. We also thank Boehringer Ingelheim $\mathrm{GmbH}$, GlaxoSmithKline and Novartis for funding the study. The PLATINO study has been sponsored by ALAT, Boehringer Ingelheim $\mathrm{GmbH}$, GlaxoSmithKline and Novartis for the collection of the data during the field work. The PLATINO group for this project included Dolores Moreno (Pulmonary Division, Hospital Universitario de Caracas, Universidad Central de Venezuela, Caracas, Venezuela), Julio Pertuze (Pontificia Universidad Catolica de Chile), Carmen Lisboa (Pontificia Universidad Catolica de Chile), and Oliver A Nascimento, Mariana R Gazzotti, Graciane Laender, and Beatriz Manzano (Federal University of Sao Paulo -Brazil).

\section{Author contributions}

AMB Menezes coordinated the PLATINO study. MV Lopez and A Muiño were the principal investigators (PIs) in the 
follow-up in Montevideo. G Valdivia was the PI in Santiago. JR Jardim was the PI in São Paulo. M Montes de Oca was the PI in the PLATINO baseline in Caracas. R Perez-Padilla was responsible for the spirometry control, wrote the first draft of the manuscript with AMB Menezes and FC Wehrmeister and conducted with FC Wehrmeister the statistical analysis. All authors contributed toward data analysis, drafting and critically revising the paper, gave final approval of the version to be published, and agree to be accountable for all aspects of the work.

\section{Disclosure}

The authors report no conflicts of interest in this work.

\section{References}

1. GBD 2016 Causes of Death Collaborators. Global, regional, and national age-sex specific mortality for 264 causes of death, 1980-2016: a systematic analysis for the Global Burden of Disease Study 2016. Lancet. 2017;390(10100):1151-1210.

2. Lange P, Celli B, Agustí A, et al. Lung-Function Trajectories Leading to Chronic Obstructive Pulmonary Disease. N Engl J Med. 2015; 373(2):111-122.

3. Menezes AM, Perez-Padilla R, Jardim JR, et al. Chronic obstructive pulmonary disease in five Latin American cities (the PLATINO study): a prevalence study. Lancet. 2005;366(9500):1875-1881.

4. Menezes AM, Pérez-Padilla R, Wehrmeister FC, et al. FEV1 is a better predictor of mortality than FVC: the PLATINO cohort study. PLoS One. 2014;9(10):e109732.

5. GOLD. Global Strategy for the Diagnosis, Management and Prevention of COPD. Global Initiative for Chronic Obstructive Lung Disease (GOLD); 2018. Available from: https://goldcopd.org/wp-content/ uploads/2017/11/GOLD-2018-v6.0-FINAL-revised-20-Nov_WMS. pdf. Accessed September 24, 2018.

6. Buist AS, McBurnie MA, Vollmer WM, et al. International variation in the prevalence of COPD (the BOLD Study): a population-based prevalence study. Lancet. 2007;370(9589):741-750.

7. Hardie JA, Buist AS, Vollmer WM, Ellingsen I, Bakke PS, Mørkve O. Risk of over-diagnosis of COPD in asymptomatic elderly neversmokers. Eur Respir J. 2002;20(5):1117-1122.

8. Pérez-Padilla R, Fernandez-Plata R, Montes de Oca M, et al. Lung function decline in subjects with and without COPD in a populationbased cohort in Latin-America. PLoS One. 2017;12(5):e0177032.

9. Bridevaux PO, Gerbase MW, Probst-Hensch NM, Schindler C, Gaspoz JM, Rochat T. Long-term decline in lung function, utilisation of care and quality of life in modified GOLD stage 1 COPD. Thorax. 2008;63(9):768-774.

10. Dransfield MT, Kunisaki KM, Strand MJ, et al. Acute Exacerbations and Lung Function Loss in Smokers with and without Chronic Obstructive Pulmonary Disease. Am J Respir Crit Care Med. 2017;195(3): 324-330.

11. Rodriguez-Roisin R, Han MK, Vestbo J, Wedzicha JA, Woodruff PG, Martinez FJ. Chronic respiratory symptoms with normal spirometry. A reliable clinical entity? Am J Respir Crit Care Med. 2017; 195(1):17-22.

12. Rossi A, Butorac-Petanjek B, Chilosi M, et al. Chronic obstructive pulmonary disease with mild airflow limitation: current knowledge and proposal for future research - a consensus document from six scientific societies. Int J Chron Obstruct Pulmon Dis. 2017;12: 2593-2610.

13. Celli BR, Decramer M, Wedzicha JA, et al. An official American Thoracic Society/European Respiratory Society Statement: Research questions in chronic obstructive pulmonary disease. Am J Respir Crit Care Med. 2015;191(7):e4-e27.
14. Menezes AM, Victora CG, Perez-Padilla R; PLATINO Team. The Platino project: methodology of a multicenter prevalence survey of chronic obstructive pulmonary disease in major Latin American cities. BMC Med Res Methodol. 2004;4:15.

15. Menezes AM, Muiño A, López-Varela MV, et al. A populationbased cohort study on chronic obstructive pulmonary disease in Latin America: methods and preliminary results. The PLATINO Study Phase II. Arch Bronconeumol. 2014;50(1):10-17.

16. Spirometry Sof. Update. American Thoracic Society. Am J Respir Crit Care Med. 1995;152:1107-1136.

17. Mannino DM, Buist AS, Petty TL, Enright PL, Redd SC. Lung function and mortality in the United States: data from the First National Health and Nutrition Examination Survey follow up study. Thorax. 2003;58(5):388-393.

18. Montes de Oca M, Tálamo C, Halbert RJ, et al. Frequency of self-reported COPD exacerbation and airflow obstruction in five Latin American cities: the Proyecto Latinoamericano de Investigacion en Obstruccion Pulmonar (PLATINO) study. Chest. 2009;136(1):71-78.

19. de Oca MM, Halbert RJ, Lopez MV, et al. The chronic bronchitis phenotype in subjects with and without COPD: the PLATINO study. Eur Respir J. 2012;40(1):28-36.

20. Corrado A, Rossi A. How far is real life from COPD therapy guidelines? An Italian observational study. Respir Med. 2012;106(7):989-997.

21. Screening for chronic obstructive pulmonary disease using spirometry: recommendation statement. Am Fam Physician. 2009;80(8):853.

22. US Preventive Services Task Force. Screening for Chronic Obstructive Pulmonary Disease: Recommendation Statement. Am Fam Physician. 2016;94(2).

23. Franco-Marina F, Fernandez-Plata R, Torre-Bouscoulet L, et al. Efficient screening for COPD using three steps: a cross-sectional study in Mexico City. NPJ Prim Care Respir Med. 2014;24:14002.

24. Perez-Padilla R, Vollmer WM, Vázquez-García JC, et al. Can a normal peak expiratory flow exclude severe chronic obstructive pulmonary disease? Int J Tuberc Lung Dis. 2009;13(3):387.

25. Burtscher M, Haider T, Domej W, et al. Intermittent hypoxia increases exercise tolerance in patients at risk for or with mild COPD. Respir Physiol Neurobiol. 2009;165(1):97-103.

26. Chavannes N, Vollenberg JJ, van Schayck CP, Wouters EF. Effects of physical activity in mild to moderate COPD: a systematic review. Br J Gen Pract. 2002;52(480):574-578.

27. Chen S, Wang C, Li B, et al. Risk factors for $\mathrm{FEV}_{1}$ decline in mild COPD and high-risk populations. Int J Chron Obstruct Pulmon Dis. 2017;12:435-442.

28. Elbehairy AF, Webb KA, Neder JA, Alberto Neder J, O'Donnell DE. Should mild COPD be treated? Evidence for early pharmacological intervention. Drugs. 2013;73(18):1991-2001.

29. Jácome C, Marques A. Impact of pulmonary rehabilitation in subjects with mild COPD. Respir Care. 2014;59(10):1577-1582.

30. Neder JA, O'Donnell CD, Cory J, et al. Ventilation Distribution Heterogeneity at Rest as a Marker of Exercise Impairment in Mild-toAdvanced COPD. COPD. 2015;12(3):252-259.

31. O'Donnell DE, Neder JA, Elbehairy AF. Physiological impairment in mild COPD. Respirology. 2016;21(2):211-223.

32. Elbehairy AF, Guenette JA, Faisal A, et al. Mechanisms of exertional dyspnoea in symptomatic smokers without COPD. Eur Respir J. 2016;48(3):694-705.

33. Jones JH, Zelt JT, Hirai DM, et al. Emphysema on Thoracic CT and Exercise Ventilatory Inefficiency in Mild-to-Moderate COPD. COPD. 2017;14(2):210-218.

34. Regan EA, Lynch DA, Curran-Everett D, et al. Clinical and Radiologic Disease in Smokers With Normal Spirometry. JAMA Intern Med. 2015; 175(9):1539-1549.

35. Lee JH, Cho MH, McDonald ML, et al. Phenotypic and genetic heterogeneity among subjects with mild airflow obstruction in COPDGene. Respir Med. 2014;108(10):1469-1480.

36. Proyecto Latinoamericano de Investigación en Obstrucción Pulmonar (PLATINO). PLATINO Questionnaire. Available from: http://www. platino-alat.org/docs/cuestionario_platino_mexico.pdf. Accessed September 24, 2018. Spanish. 


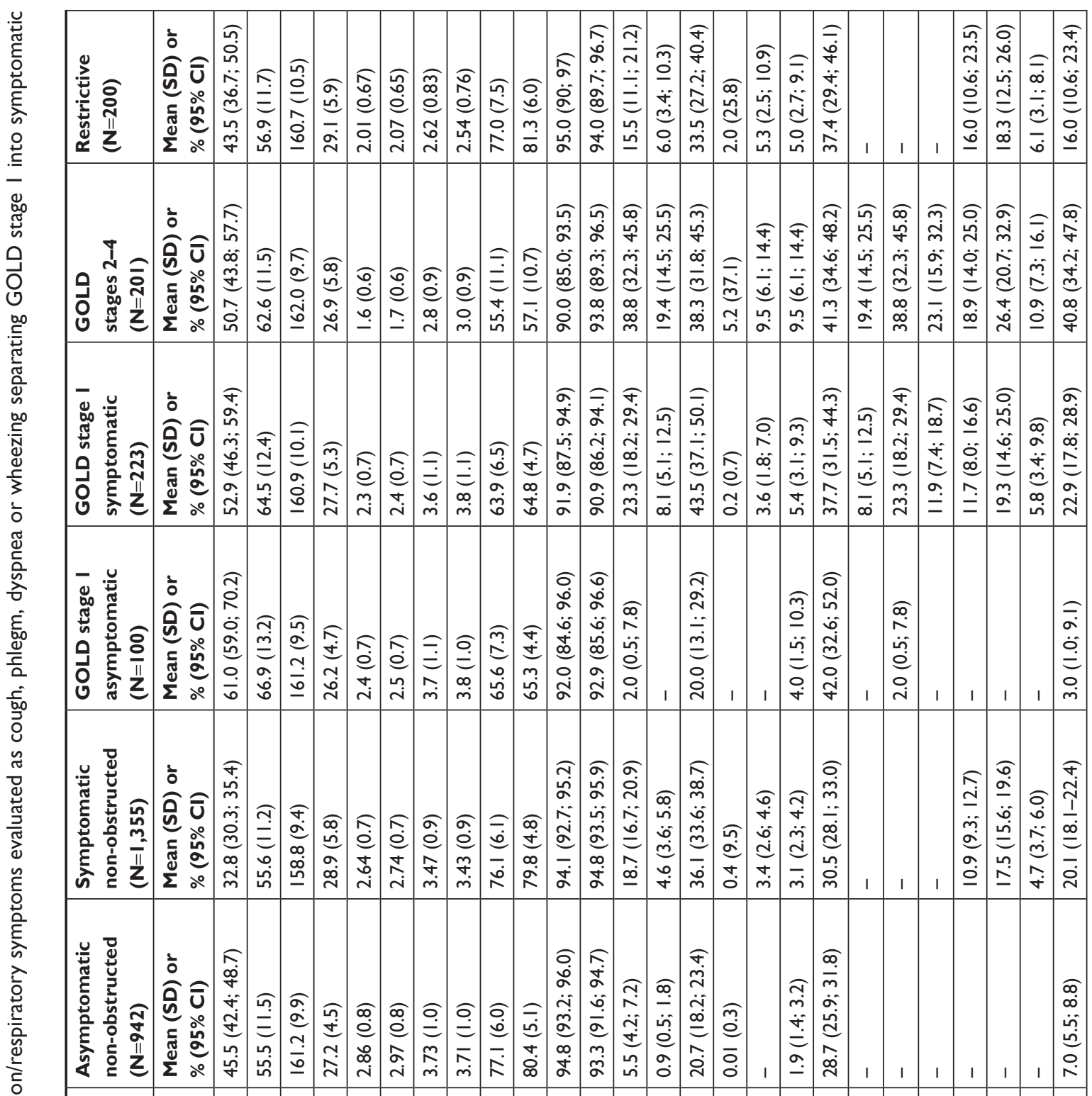




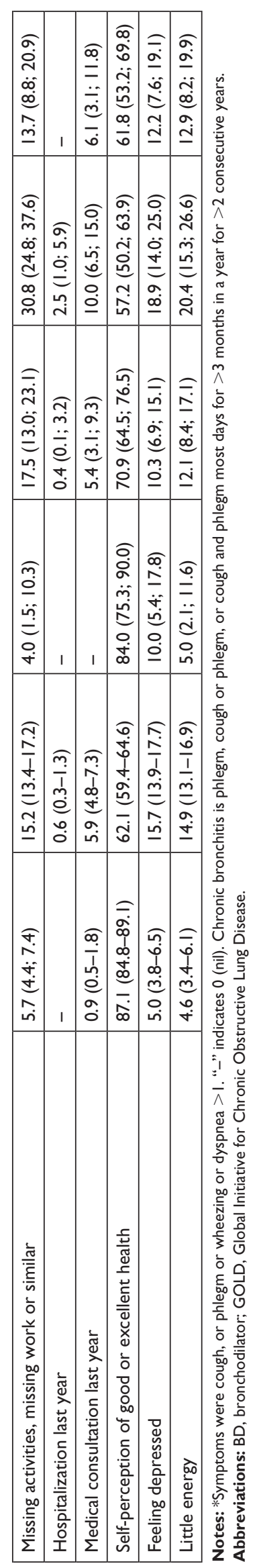


Table S2 Adjusted association (OR 95\% Cl) between GOLD stage at baseline, deaths, lung function decline and exacerbations in the follow-up visit

\begin{tabular}{|c|c|c|c|c|c|c|}
\hline & \multicolumn{2}{|l|}{ Unadjusted } & \multicolumn{2}{|l|}{ Adjusted I } & \multicolumn{2}{|l|}{ Adjusted 2} \\
\hline & \multicolumn{6}{|l|}{ Deaths } \\
\hline & HR (95\% CI) & $P$-value & HR (95\% CI) & $P$-value & HR (95\% CI) & $P$-value \\
\hline NO asymptomatic & I.00 (reference) & & I.00 (reference) & & I.00 (reference) & \\
\hline $\mathrm{NO} /$ symptomatic & I.4I $(0.98,2.0)$ & 0.06 & $1.35(0.94,1.95)$ & 0.102 & $1.31(0.89,1.92)$ & 0.16 \\
\hline GOLD I asymptomatic & $3.7 \mathrm{I}(2.07,6.67)$ & $<0.001$ & $1.64(0.90,2.97)$ & 0.100 & $1.62(0.89,2.99)$ & 0.116 \\
\hline GOLD I symptomatic & $3.23(2.11,5.2)$ & $<0.001$ & $1.49(0.94,2.35)$ & 0.088 & I.38 $(0.84,2.27)$ & 0.201 \\
\hline \multirow[t]{3}{*}{ GOLD 2-4 } & $5.6(3.72,8.48)$ & $<0.001$ & $2.95(1.94,4.50)$ & $<0.001$ & $2.09(1.18,3.68)$ & 0.011 \\
\hline & \multicolumn{6}{|c|}{ FEV, post-BD decline } \\
\hline & $\beta(95 \% \mathrm{Cl})$ & $P$-value & $\beta(95 \% \mathrm{Cl})$ & $P$-value & $\beta(95 \% \mathrm{Cl})$ & $P$-value \\
\hline $\mathrm{NO} /$ symptomatic & $-0.84(-4.86,3.18)$ & 0.682 & $-3.66(-7.8,0.48)$ & 0.08 & $-4.5(-8.7,-0.40)$ & 0.030 \\
\hline GOLD I asymptomatic & $2.65(-8.4,13.7)$ & 0.638 & $6.0(-5.07,17.15)$ & 0.287 & $0.6(-10.7,11.9)$ & 0.917 \\
\hline GOLD I symptomatic & $-2.64(-10.0,4.7)$ & 0.480 & $-2.9(-10.46,4.6)$ & 0.444 & $-6.5(-14.1,1.1)$ & 0.09 \\
\hline \multirow[t]{3}{*}{ GOLD 2-4 } & $4.2(-4.0,12.3)$ & 0.318 & $4.4(-3.8,12.7)$ & 0.288 & $-8.2(-17.5,1.13)$ & 0.085 \\
\hline & \multicolumn{6}{|c|}{$2+$ exacerbations in the year before second evaluation } \\
\hline & OR $(95 \% \mathrm{Cl})$ & $P$-value & OR $(95 \% \mathrm{Cl})$ & $P$-value & OR $(95 \% \mathrm{CI})$ & $P$-value \\
\hline NO/symptomatic & $4.03(1.8,9.1)$ & 0.001 & $2.84(1.23,6.5)$ & 0.014 & $2.58(1.11,5.99)$ & 0.026 \\
\hline GOLD I asymptomatic & - & & - & & - & \\
\hline GOLD I symptomatic & $3.44(\mathrm{I} . \mathrm{I}, \mathrm{I} \mathrm{I} .0)$ & 0.037 & $3.39(1.01,11.3)$ & 0.047 & $1.87(0.52,6.85)$ & 0.340 \\
\hline GOLD 2-4 & $7.47(2.65,21.0)$ & $<0.001$ & $7.56(2.56,22.3)$ & 0.004 & $1.50(0.40,5.6)$ & 0.542 \\
\hline
\end{tabular}

Notes: Symptoms = cough, phlegm, dyspnea Medical Research Council (MRC) > I or wheezing in last year. $95 \% \mathrm{Cl}, 95 \%$ confidence interval; inconsistent, different result between the two examinations. The unadjusted model includes the restricted group (not shown). I) adjusted by age, gender, BMI and education, comorbidities, restricted group and after the first line by smoking (pack-years and cigarettes/day). 2) adjusted model I + FEV (post-BD). “-” indicates 0 (nil).

Abbreviations: BD, bronchodilator; GOLD, Global Initiative for Chronic Obstructive Lung Disease; NO, non-obstructive.

Table S3 Associations between the presence of symptoms and several risk factors

\begin{tabular}{|c|c|c|c|c|c|c|c|c|}
\hline $\begin{array}{l}\text { Risk factors for } \\
\text { symptoms }\end{array}$ & $\begin{array}{l}\text { Cough/ } \\
\text { phlegm }\end{array}$ & $95 \% \mathrm{Cl}$ & $\begin{array}{l}\text { CB cough/ } \\
\text { phlegm }\end{array}$ & $95 \% \mathrm{Cl}$ & $\begin{array}{l}\text { Cough/ } \\
\text { phlegm/ } \\
\text { dyspnea }\end{array}$ & $95 \% \mathrm{Cl}$ & $\begin{array}{l}\text { Cough/phlegm/ } \\
\text { dyspnea/wheezing }\end{array}$ & $95 \% \mathrm{Cl}$ \\
\hline Asthma & $2.22 *$ & I.77, 2.77 & $2.66^{*}$ & $2.03,3.49$ & $2.19 *$ & $1.69,2.84$ & $4.7^{*}$ & $3.5,6.3$ \\
\hline Wheezing last year & $3.06 *$ & $2.55,3.67$ & $3.67 *$ & $2.86,4.71$ & $3.26 *$ & $2.66,3.99$ & NA & NA \\
\hline Current smoking & $2.12 *$ & $1.76,2.56$ & $1.59 *$ & $1.22,2.06$ & $2.27^{*}$ & I.87, 2.74 & $3.1^{*}$ & $2.6,3.8$ \\
\hline Heart disease & $1.51 *$ & $1.21,1.89$ & 1.07 & $0.78,1.46$ & $2.08^{*}$ & $1.64,2.64$ & $2.16^{*}$ & $1.65,2.82$ \\
\hline Passive smoking & 1.19 & $0.99,1.41$ & 1.11 & $0.86,1.41$ & $1.30 *$ & $1.09,1.54$ & $1.23^{*}$ & $1.01,1.50$ \\
\hline $\begin{array}{l}\text { Work in a dusty } \\
\text { or smoky place }\end{array}$ & $1.19 *$ & $1.00,1.41$ & 1.27 & $0.99,1.63$ & 1.30 & I.I0, I.54 & $1.46^{*}$ & $1.2,1.7$ \\
\hline
\end{tabular}

Notes: Models were also adjusted by BMl, education, age and diabetes. Pseudo $R^{2}$ was between $13.8 \%$ and $I 1.8 \%$. $* P<0.05$. Asthma, heart disease and diabetes were previous physician diagnoses referred by individuals. CB cough/phlegm is cough or phlegm most days of 3 months for $>2$ consecutive years. Cough/phlegm is cough or phlegm in general even without colds. Wheezing is the report of wheezing in the last year. Dyspnea is score $>I$ in the Medical Research Council (MRC) scale.

Abbreviations: $\mathrm{CB}$, chronic bronchitis; NA, not applicable. 


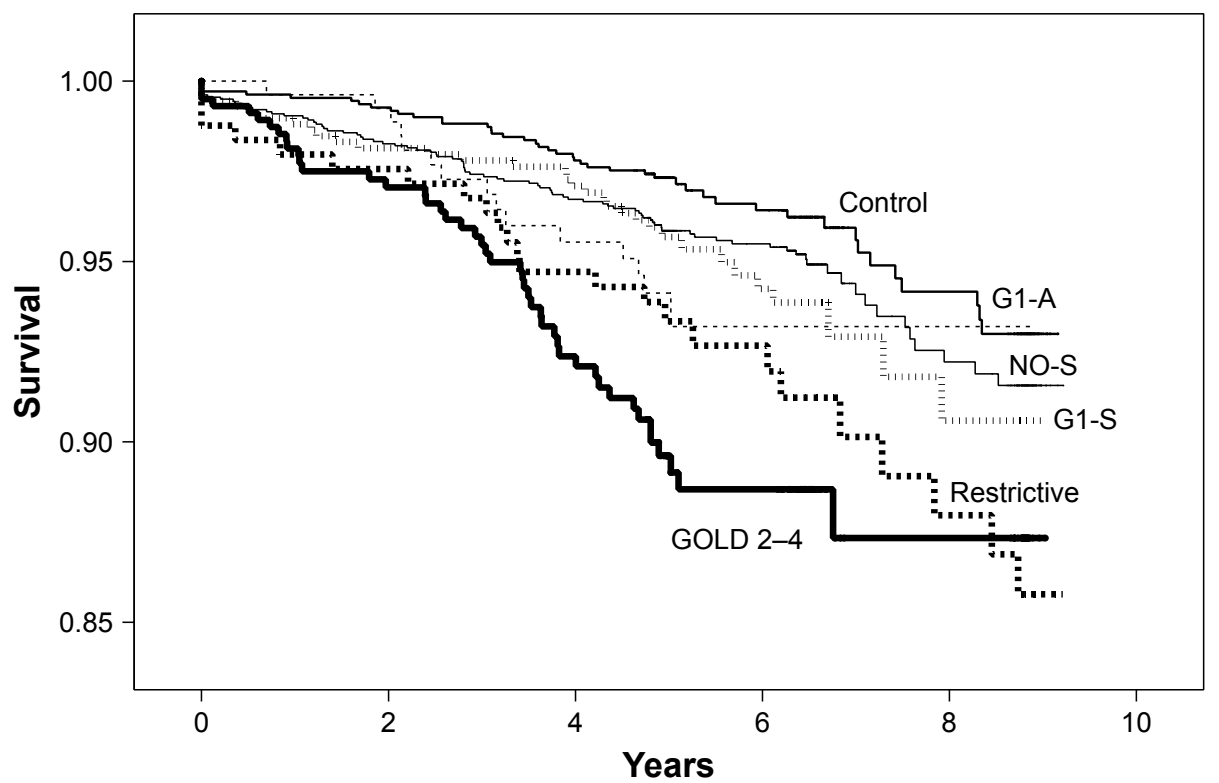

Figure SI Survival curves of non-obstructed non-restricted individuals with respiratory symptoms (cough, phlegm, dyspnea or wheezing), non-obstructed symptomatic (NO-S) and asymptomatic (Control), compared with those with spirometric restrictive pattern and airflow obstruction GOLD stage I, with symptoms (GI-S) and asymptomatic (GI-A), and GOLD stages 2-4 (GOLD 2-4), adjusted by mean age (57 years), feminine gender, education, pack-years of smoking and comorbidities (as in Adjusted I, Table S2).

Notes: Non-obstructed symptomatic individuals (NO-S) had less survival than controls and stage-I asymptomatic individuals but better outcome than individuals with moderate-to-severe airflow obstruction, and restrictive pattern. In Table SI, the characteristics of each group, including the participants, are depicted.

Abbreviation: GOLD, Global Initiative for Chronic Obstructive Lung Disease.

Table S4 Predictors of incident COPD, GOLD stages 2-4

\begin{tabular}{|l|l|l|}
\hline Category at baseline & $\begin{array}{l}\text { Individuals with } \\
\text { incident GOLD 2-4 }\end{array}$ & $\%$ \\
\hline Non-obstructed/asymptomatic & $7 / 679$ & 1.0 \\
\hline Non-obstructed/symptomatic & $15 / 951$ & 1.6 \\
\hline GOLD I asymptomatic & $4 / 55$ & 7.3 \\
\hline GOLD I symptomatic & $21 / 139$ & 15.1 \\
\hline Restricted & $7 / 116$ & 6.0 \\
\hline Total & $54 / 2,051$ & 2.6 \\
\hline
\end{tabular}

Notes: Incident cases were those present in the second evaluation but not at baseline. Symptoms considered were cough or phlegm or dyspnea $>$ I, or wheezing in the last year. Symptomatic groups, have more incidence of COPD GOLD stages $2-4$. $P<0.00$ I Fisher exact test.

Abbreviation: GOLD, Global Initiative for Chronic Obstructive Lung Disease.

Table S5 Predictors of incident GOLD 2-4

\begin{tabular}{|c|c|c|c|c|c|c|c|c|}
\hline \multirow{2}{*}{$\begin{array}{l}\text { Characteristics at baseline } \\
\text { Symptoms (cough, phlegm, dyspnea or wheezing) }\end{array}$} & \multirow{2}{*}{$\begin{array}{l}\text { Model I } \\
\text { OR } \\
2.08\end{array}$} & \multicolumn{2}{|c|}{$95 \% \mathrm{Cl}$} & \multirow{2}{*}{$\begin{array}{l}\text { P-value } \\
0.045 \\
\end{array}$} & \multirow{2}{*}{$\begin{array}{l}\text { Model } 2 \\
\text { OR } \\
1.59\end{array}$} & \multicolumn{2}{|c|}{$95 \% \mathrm{Cl}$} & \multirow{2}{*}{$\begin{array}{l}P \text {-value } \\
0.217 \\
\end{array}$} \\
\hline & & 1.02 & 4.25 & & & 0.76 & 3.30 & \\
\hline Years at school & 0.91 & 0.86 & 0.97 & 0.006 & 0.96 & 0.90 & 1.02 & 0.192 \\
\hline BMI $\left(\mathrm{kg} / \mathrm{m}^{2}\right)$ & 0.95 & 0.89 & 1.01 & 0.076 & 0.95 & 0.90 & 1.01 & 0.081 \\
\hline Asthma (Physician diagnosis) & 2.91 & 1.54 & 5.50 & 0.001 & 2.06 & 1.07 & 3.98 & 0.032 \\
\hline Masculine gender & 2.50 & 1.37 & 4.54 & 0.003 & 4.55 & 2.39 & 8.65 & 0.000 \\
\hline Current smoker & 1.82 & 1.02 & 3.24 & 0.042 & 1.97 & 1.09 & 3.55 & 0.024 \\
\hline Dusty or smoky occupation & 0.64 & 0.36 & 1.13 & 0.122 & & & & \\
\hline FEV , post $\mathrm{BD}(\mathrm{L})$ & & & & & 0.34 & 0.21 & 0.55 & 0.000 \\
\hline Constant & 0.07 & 0.01 & 0.43 & 0.004 & 0.57 & 0.08 & 4.22 & 0.581 \\
\hline Pseudo $R^{2}$ & $8.2 \%$ & & & & $11.9 \%$ & & & \\
\hline
\end{tabular}

Notes: Model 2 differs from Model I only in the inclusion of FEV , post-BD at baseline. Best predictor of developing GOLD stage 2-4 COPD was previous FEV . Adjusting by $\mathrm{FEV}$, the impact of symptoms is reduced and becomes non-significant. Masculine gender, smoking and asthma still predict incident GOLD 2-4 even adjusting by FEV . Values shown in bold emphasize results that are statistically significant.

Abbreviations: BD, bronchodilator; GOLD, Global Initiative for Chronic Obstructive Lung Disease. 
International Journal of COPD

\section{Publish your work in this journal}

The International Journal of COPD is an international, peer-reviewed journal of therapeutics and pharmacology focusing on concise rapid reporting of clinical studies and reviews in COPD. Special focus is given to the pathophysiological processes underlying the disease, intervention programs, patient focused education, and self management protocols.

This journal is indexed on PubMed Central, MedLine and CAS. The manuscript management system is completely online and includes a very quick and fair peer-review system, which is all easy to use. Visit http://www.dovepress.com/testimonials.php to read real quotes from published authors 